\title{
Layer by Layer Self-Assembled Polyelectrolyte Multilayers with Embedded \\ Phospholipid Vesicles obtained by Spraying : Integrity of the Vesicles
}

M. Michel ${ }^{1,2}$, A. Izquierdo ${ }^{2}$, G. Decher ${ }^{2}$, J.-C. Voegel ${ }^{1}$, P. Schaaf ${ }^{2, *}$, V. Ball ${ }^{1}$

1 : Institut National de la Santé et de la Recherche Médicale

Unité 595

Faculté de Médecine.

11 rue Humann.

67085 Strasbourg Cedex.

2 : Centre National de la Recherche Scientifique.

Unité Propre 22, Institut Charles Sadron.

6 rue Boussingault.

67083 Strasbourg Cedex.

* : to whom all correspondance should be addressed.

Phone : 0033388414001

Fax : 0033388414099

\section{Supporting information.}

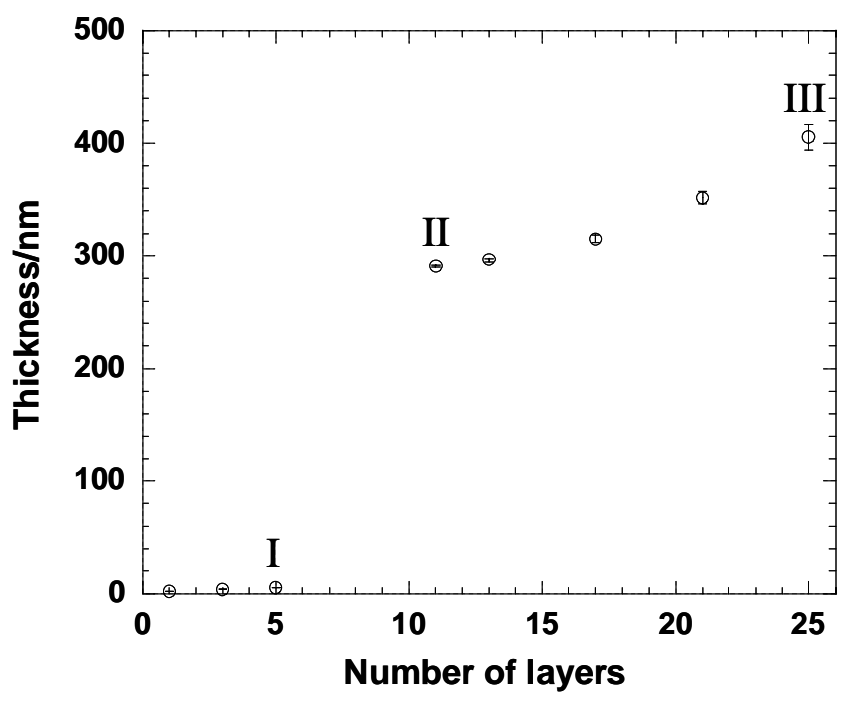

Figure 1: Evolution of the thickness increase of a PEI-(PGA/PAH $)_{2}-(P G A / S V)-(P G A / P A H)_{9}$ multilayer obtained by the alternated spraying method. The different steps corresponds to the deposition of : Step I: PEI-(PGA/PAH); Step II: Step I +(PGA/SV)-(PGA/PAH $)_{2}$; Step III: Step II $+(\mathrm{PGA} / \mathrm{PAH})_{7}$ 


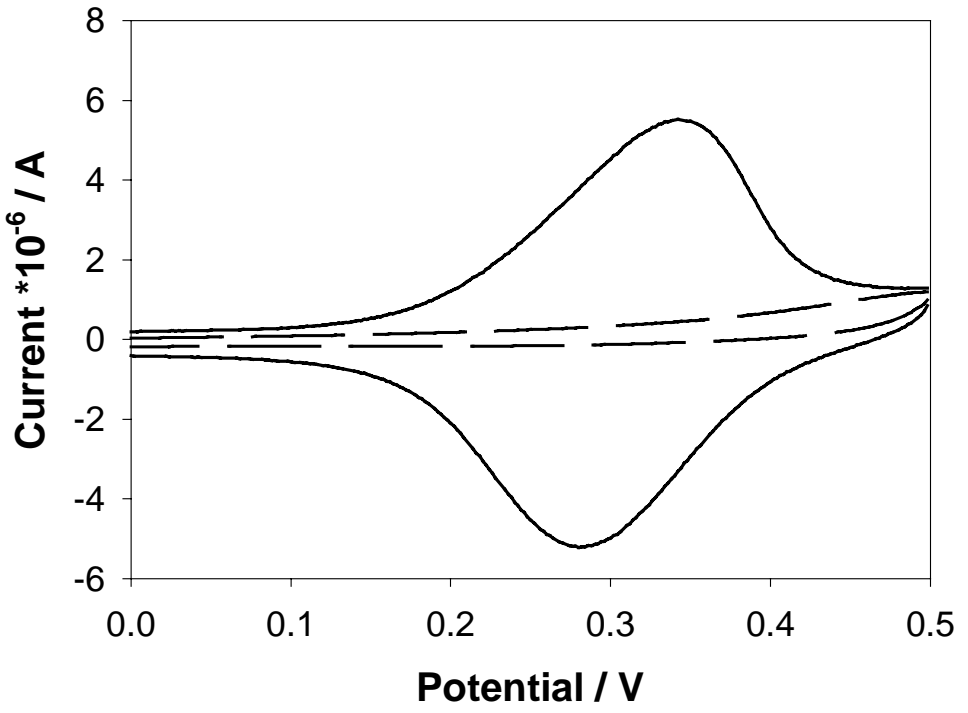

Figure 2: Cyclic voltamograms on the surface of a gold electrode covered with a PEI-(PGA/PAH $)_{5}$ multilayer onto which a $1 \mathrm{mM} \mathrm{Fe}(\mathrm{CN})_{6}{ }^{4-}$ solution was sprayed. Dashed line: capacitive current obtained before ferrocyanide spraying. Full line: $1 \mathrm{~min}$. after spraying. The scan rate was equal to $200 \mathrm{mV} \cdot \mathrm{s}^{-1}$.

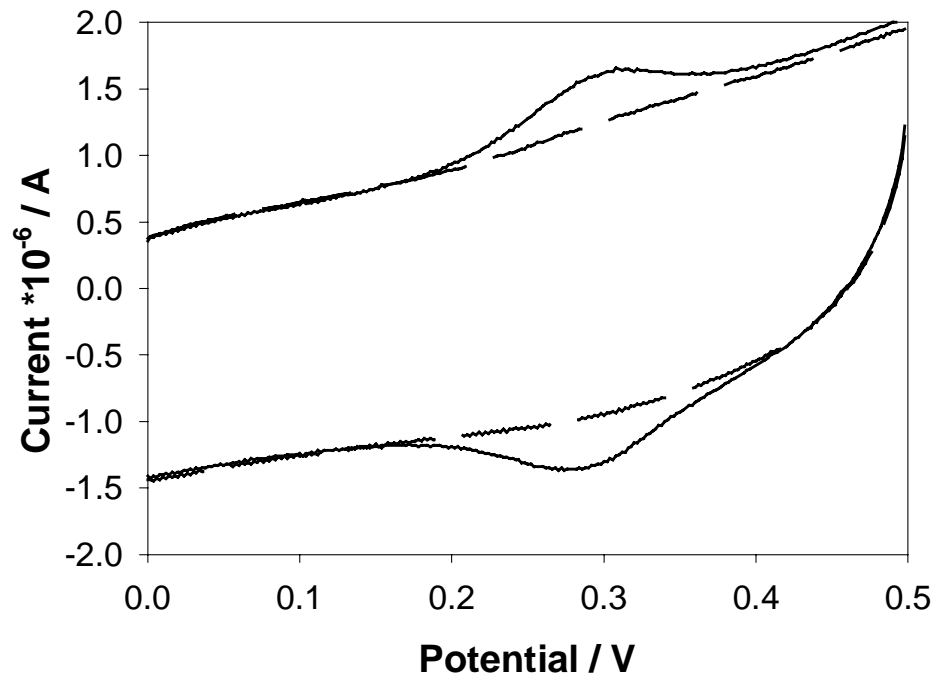

Figure 3: Cyclic voltamograms on the surface of a gold electrode onto which a PEI-(PGA/PAH $)_{2}-$ $(\mathrm{NSV} / \mathrm{PAH})-(\mathrm{PGA} / \mathrm{PAH})_{2}$ film was sprayed. In this experiment, the vesicles contained ferrocyanide ions.

Dashed line: signal for PEI-(PGA/PAH $)_{2}$ before spraying the non stabilized vesicles (capacitive current); full line: cyclic voltamogram obtained about 1 min. after film build up was achieved including non stabilized vesicles. The scan rate was equal to $200 \mathrm{mV} . \mathrm{s}^{-1}$. 


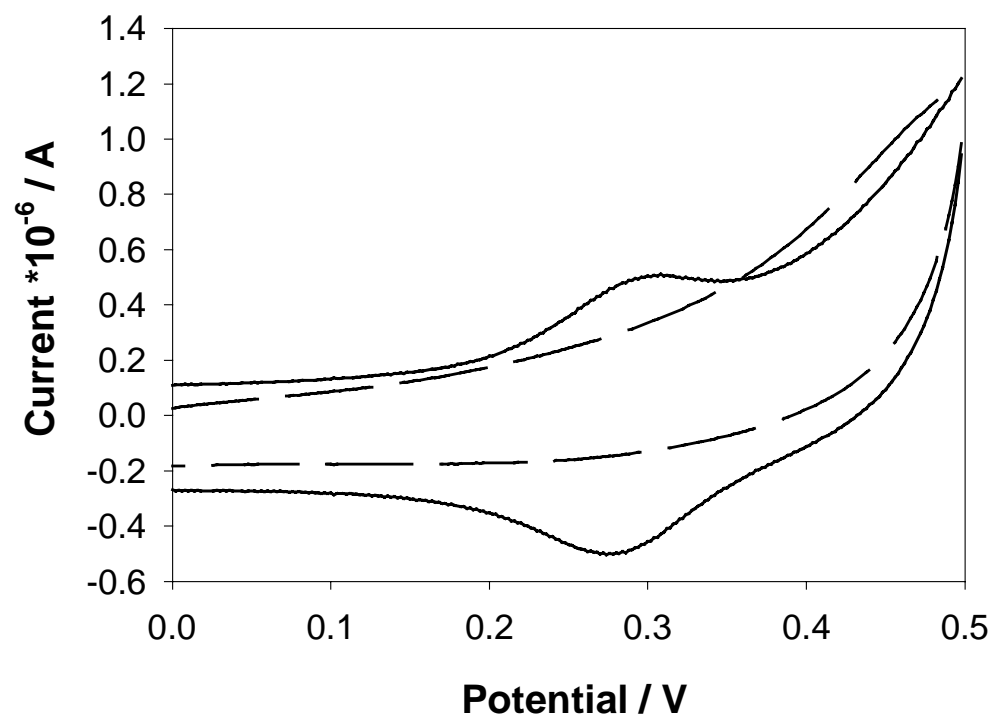

Figure 4: Cyclic voltamograms of a gold electrode covered with a PEI-(PGA/PAH $)_{2}-P G A$ film onto which stabilized vesicles (SV) were sprayed and kept uncovered. Dashed line: signal obtained before spraying the SV (capacitive current); full line: cyclic voltamogram obtained about 1 min after SV spraying was achieved. The scan rate was equal to $200 \mathrm{mV} . \mathrm{s}^{-1}$. 